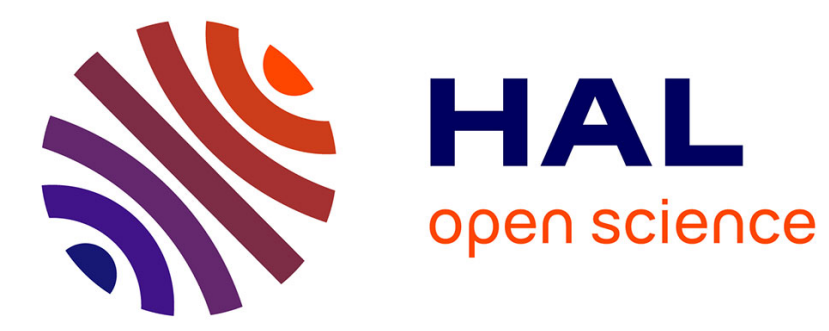

\title{
Vertical structure of the midlatitude temperature from stratosphere to mesopause $(30-105 \mathrm{~km})$
}

C. Y. She, J. R. Yu, David A. Krueger, Raymond Roble, Philippe Keckhut, Alain Hauchecorne, Marie-Lise Chanin

\section{- To cite this version:}

C. Y. She, J. R. Yu, David A. Krueger, Raymond Roble, Philippe Keckhut, et al.. Vertical structure of the midlatitude temperature from stratosphere to mesopause (30-105 km). Geophysical Research Letters, 1995, 22 (4), pp.377-380. 10.1029/95GL00010 . insu-03132110

\section{HAL Id: insu-03132110 \\ https://hal-insu.archives-ouvertes.fr/insu-03132110}

Submitted on 5 Feb 2021

HAL is a multi-disciplinary open access archive for the deposit and dissemination of scientific research documents, whether they are published or not. The documents may come from teaching and research institutions in France or abroad, or from public or private research centers.
L'archive ouverte pluridisciplinaire HAL, est destinée au dépôt et à la diffusion de documents scientifiques de niveau recherche, publiés ou non, émanant des établissements d'enseignement et de recherche français ou étrangers, des laboratoires publics ou privés. 


\title{
Vertical structure of the midlatitude temperature from stratosphere to mesopause $(30-105 \mathrm{~km})$
}

\author{
C. Y. She, J. R. Yu and David A. Krueger \\ Physics Department, Colorado State University, Fort Collins, CO 80523, USA
}

Raymond Roble

National Center for Atmospheric Research, Boulder, CO 80307, USA

Philippe Keckhut, Alain Hauchecorne and Marie-Lise Chanin

Service d'Aeronomie du CNRS, Verrieres le Buisson Cedex, 91371, France

\begin{abstract}
Data sets from Rayleigh lidar (1979-93) at the Observatory of Haute-Provence $\left(44^{\circ} \mathrm{N}, 6^{\circ} \mathrm{E}\right)$ and at Biscarrosse $\left(44^{\circ} \mathrm{N}, 1^{\circ} \mathrm{W}\right)$ of southern France, and from narrowband Na lidar (1991-4) at Fort Collins, Colorado $\left(41^{\circ} \mathrm{N}, 105^{\circ} \mathrm{W}\right)$ are used to deduce the vertical temperature structure of the midlatitude middle atmosphere from 30 $105 \mathrm{~km}$. Nightly averaged temperatures measured across the Atlantic at comparable latitudes between 81 and $90 \mathrm{~km}$ showed seasonal variations tracking one another. Harmonic analyses of the measured profiles at these sites have been compared to the reference atmosphere, CIRA 1986. Considerable differences are noted in the annual mean temperatures in the mesopause region. Two temperature minima at 86 and $99 \mathrm{~km}$ are observed, suggesting heating and cooling mechanisms not previously incorporated into the reference atmosphere. Using the new 3D TIME-GCM of Roble and Ridley which includes both dynamical and chemical processes, we account for this anomalous behavior by model simulation for the first time. Except the existence of strong semi-annual oscillations, the observed annual and semi-annual temperature variations are compatible with CIRA 1986. Observed annual temperature and solar flux forcing are out-of-phase between 65 and $99 \mathrm{~km}$, reflecting a dynamics dominated atmosphere at these altitudes.
\end{abstract}

\section{Introduction}

Over the past decade, ground-based lidar sounding of atmospheric temperatures has gained acceptance. Fourteen years of quality temperature data with $\sim 100$ nights per year by Rayleigh lidar at the Observatory of Haute-Provence (OHP) and Biscarrosse (BIS), southern France [Hauchecorne et al., 19911, and three years of quality data, with $\sim 50$ nights per year by narrowband $\mathrm{Na}$ fluorescence lidar at Fort Collins (FC), Colorado [Yu and She, 1995] have already been collected. Using these data sets the climatology of the midlatitude middle atmosphere may be investigated.

The much higher spatial resolution obtainable from

Copyright 1995 by the American Geophysical Union.

Paper number 95GL00010

0094-8534/95/95GL-00010\$03.00 lidar measurements coupled with its ability to better probe the mesopause region has led to the discovery of unexpectedly stable fine structure in the vertical temperature profiles at FC [She et al., 1993], which is believed to be representative of midlatitude climatology. In this paper, we first compare the nightly averaged temperatures between 81 and $90 \mathrm{~km}$ in altitudes measured by different lidar techniques across the Atlantic. We then present harmonic analyses of the vertical temperature profiles between 83 and $103 \mathrm{~km}$ over Colorado $\left(41^{\circ} \mathrm{N}, 105^{\circ} \mathrm{W}\right)$, and between 30 and $87 \mathrm{~km}$ over Southern France $\left(44^{\circ} \mathrm{N}, 1^{\circ} \mathrm{W}\right.$ and $\left.6^{\circ} \mathrm{E}\right)$ to elucidate the observed thermal structure of the mid-latitude middle atmosphere from $30-105 \mathrm{~km}$, in comparison to those deduced from the reference middle atmosphere, CIRA 1986.

\section{Nightly averaged Seasonal variations}

The nightly temperature profile derived from French Rayleigh lidar (30 to $90 \mathrm{~km}$ ) is an average of at least three hours of observation; the resolution is $3 \mathrm{~km}$ with uncertainty of $\sim 1 \mathrm{~K}, 3 \mathrm{~K}$ and $<10 \mathrm{~K}$ for altitudes between 30 and $70 \mathrm{~km}$, at $80 \mathrm{~km}$ and near $90 \mathrm{~km}$. The nightly temperature profile derived from the Colorado State narrowband Na lidar (81 to $105 \mathrm{~km}$ ) is an average of at least four hours of observation each night; the resolution is $\mathbf{1 . 5}$ $\mathrm{km}$ with uncertainty of $\sim 1 \mathrm{~K}, 3.5 \mathrm{~K}$ and $5 \mathrm{~K}$ for altitudes respectively at the peak, bottom and top of the Na layer. The mid-latitude nightly averaged temperatures (1991 to 1993) measured by different lidar techniques across the Atlantic overlap between 81 and $90 \mathrm{~km}$. Although differences in latitudes and planetary wave perturbations exist, the general trend in seasonal temperature variations at these midlatitude sites is expected to be the same.

Figure 1 compares the measured nightly averaged temperatures at $85 \mathrm{~km}$ for the Colorado site at FC and two sites in Southern France at OHP and at BIS for the threeyear period (1991 to 1993) that data exist in all three sites. The seasonal temperature variations between cool summer and warm winter are seen to track one another within the nightly variability of $\pm 8 \mathrm{~K}$ at all sites, as if they were measured from collocated lidars. Similar agreements hold for other altitudes between 82 and $89 \mathrm{~km}$. This suggests that lidar measurements at sites with different longitude but the same (or even comparable) latitude may be combined to compare with a reference atmosphere or model simulations. 


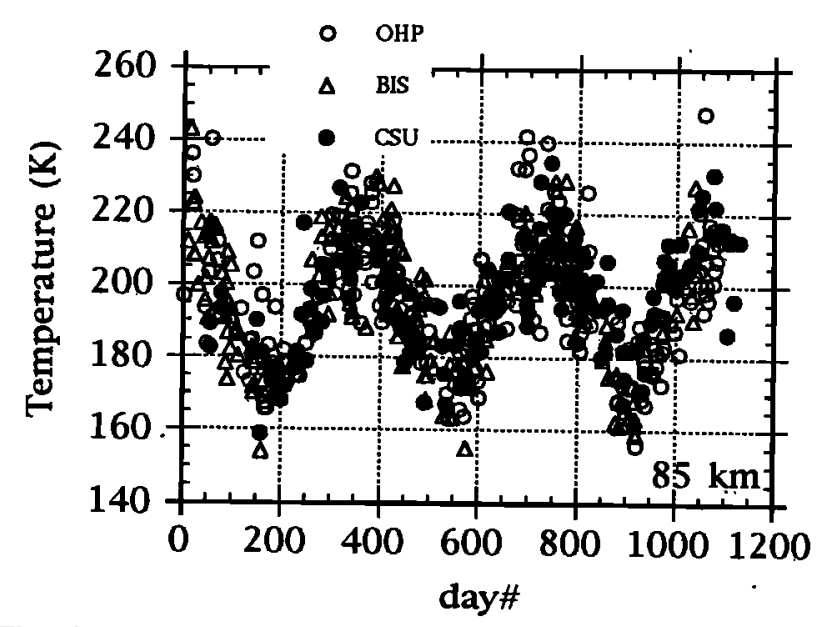

Fig. 1. Measured nightly averaged temperatures at 85 $\mathrm{km}$ at FC, OHP and BIS from 1991 to 1993. Similar ageements hold throughout the $82-90 \mathrm{~km}$ range.

\section{Harmonic analysis and measured annual mean temperatures.}

To examine the differences between the measured mean temperatures across the Atlantic, harmonic analyses on the temperature profiles are performed to determine their annual mean and the amplitudes and phases of their annual and semi-annual temperature variations. Since the distance between OHP and BIS in Southern France $(\sim 550 \mathrm{~km})$ is shorter than planetary wavelengths, we combined the data sets of the two French sites in these analyses. Both Colorado and French nightly averaged temperature profiles are first processed by smoothing with a filter of one-week resolution [Hauchecorne et al., 1991; Yu and She, 1995].

Shown in Fig. 2 in solid are the profiles of annual mean temperature determined from lidar measurements between 83 and $103 \mathrm{~km}$ over Colorado and between 30 and $87 \mathbf{~ k m}$ over Southem France. Also included for comparison are those deduced from the reference atmosphere, CIRA 1986 at $40^{\circ} \mathrm{N}$ and $45^{\circ} \mathrm{N}$. While, except for a mild systematic difference around $75 \mathrm{~km}$ [Hauchecorne et al., 1992], these profiles are in good agreement between 30 and $80 \mathrm{~km}$, considerable discrepancy exists in the mesopause region above $80 \mathrm{~km}$. The main difference is that the CIRA 1986 profiles show a single temperature minimum of 178 $\mathrm{K}$ at $94 \mathrm{~km}$, while the measured annual mean shows double temperature minima of $192 \mathrm{~K}$ and $196 \mathrm{~K}$ at 99 and $86 \mathrm{~km}$, respectively. The difference between two measured temperatures at $86 \mathrm{~km}$ is about $2 \mathrm{~K}$, within the experimental error. The lack of high resolution measurements, which compelled the CIRA 1986 to deduce the temperatures between 86 and $120 \mathrm{~km}$ from the older MSIS-83 [Hedin, 1983] empirical model of the thermosphere, is in part responsible for the discrepancy. Since the publication of the initial lidar temperature profiles [She et al., 1993] which show these double temperature minima, consistent with a temperature maximum near 90 $\mathrm{km}$ in the Solar Mesosphere Explorer (SME) data [Clancy et al., 1994], suggestion of chemical heating as the main cause of the observed temperature inversion at $\sim 90 \mathrm{~km}$
[Meriwether and Mlynzack, 1995] has been made. However, to elucidate the climatology, a more quantitative comparison using a credible simulation is needed.

\section{TIME-GCM simulation of representative seasonal temperature profiles.}

A new NCAR General Circulation Model has simulated the mesosphere, thermosphere and ionosphere with coupled electrodynamics (TIME-GCM) from 30 to 500 $\mathrm{km}$ with detailed aeronomy described in Roble and Ridley [1994], and has been used to calculate the structure of these regions over Fort Collins and lidar stations in France. Since the model is being compared with averaged data from these stations, the model is run for two hypothetical cases, perpetual equinox and solstice solar cycle minimum, geomagnetic quiet conditions.

The equinox solution is similar to the one described by Roble and Ridley [1994], and the nighttime averaged profile is shown in dash in Fig. 3(a). This temperature profile is characterized by a minimum of about $204 \mathrm{~K}$ near $83 \mathrm{~km}$, a maximum of about $208 \mathrm{~K}$ near $92 \mathrm{~km}$ and a deeper minimum of $197 \mathrm{~K}$ near $104 \mathrm{~km}$. It is attributed to a complex radiative balance in the mesospause region. $\mathrm{CO}_{2}$ infra-red cooling balances the ozone heating below about 80 $\mathrm{km}$. Between about 80 and $95 \mathrm{~km}$ heating from exothermic reactions associated with HOx chemistry as discussed by Mlynczak and Solomon [1993] produces the temperature bulge near $90 \mathrm{~km}$. Nighttime heating rates are on the order of $5-10 \mathrm{~K} / \mathrm{day}$ in this narrow altitude region. The temperature minimum near $100 \mathrm{~km}$ is caused by the strong $\mathrm{O}-\mathrm{CO}_{2}$ IR cooling with rates on the order of $50 \mathrm{~K} / \mathrm{day}$. Heating and cooling by gravity waves and turbulence are small, especially for equinox conditions. The calculated temperature profile is seen to be in qualitatively agreement with the average of the observed nightly mean temperature profiles at spring and fall equinoxes. The higher calculated temperatures may in part be the result of discrepancies between gravity wave heating and turbulent cooling as discussed in Gavrilov and Roble [1995].

The TIME-GCM was also run for solstice solar cycle

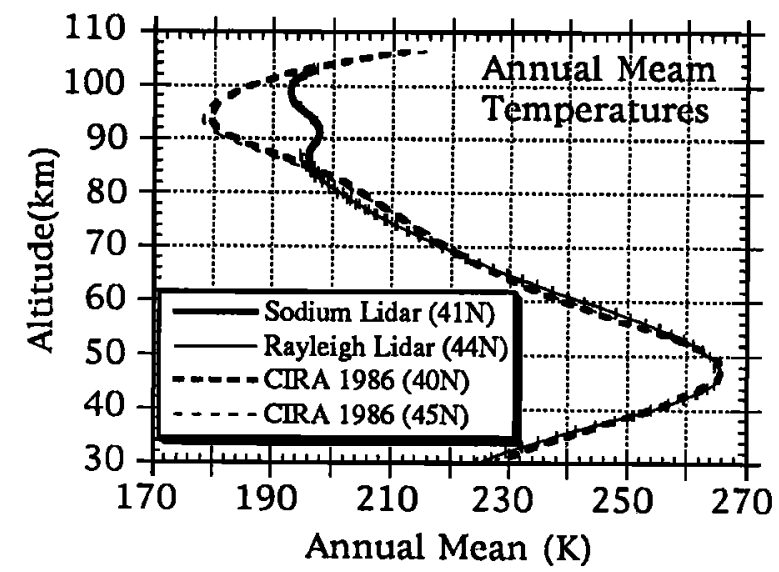

Fig. 2. Annual mean temperatures from harmonic analysis. The broad and thin solid curves are deduced from $\mathrm{Na}$ lidar $(83-103 \mathrm{~km})$ and Rayleigh lidar $(30-87 \mathrm{~km})$, respectively. The broad and thin dotted curves are from CIRA 1986 for $40^{\circ} \mathrm{N}$ and $45^{\circ} \mathrm{N}$. 

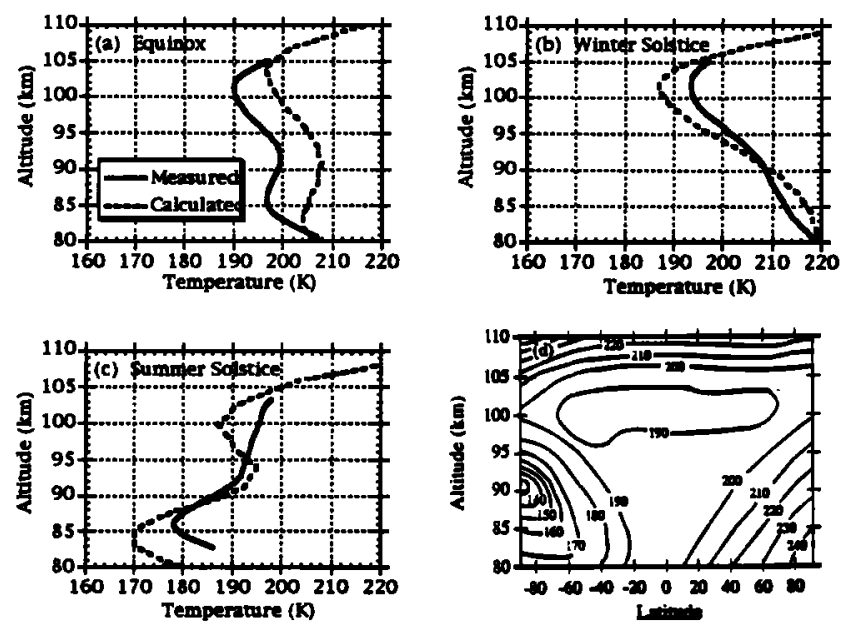

Fig.3. Calculated and measured nighttime averaged temperature profiles over Fort Collins, CO $\left(41^{\circ} \mathrm{N}, 105^{\circ} \mathrm{W}\right)$ for (a) equinox, (b) winter, (c) summer, along with calculated altitude-latitude plots of zonal mean temperature contours in the mesopause region for December solstice solar cycle minimum geomagnetic quiet conditions, in (d).

minimum geomagnetic quiet conditions. To obtain reasonable agreement with climatology it was found that the winter hemisphere required four times larger gravity wave energy flux than the summer hemisphere whose gravity wave forcing was similar to the equinox values. We did not specify any planetary wave forcing in the winter hemisphere and considered only gravity wave fluxes to close and reverse the summer and winter mesospheric jets. The calculated winter and summer nighttime averaged temperature profiles are shown in Figs 3(b) and 3(c) and compared with the observed profiles, respectively. The winter temperature profile shows a monotonic temperature decrease with increasing altitude to a single temperature minimum of $186 \mathrm{~K}$ near $102 \mathrm{~km}$ before increasing dramatically with altitude within the lower thermosphere. This profile is seen to be similar to the measured profile for winter conditions. The summer profile has a deep minimum of $170 \mathrm{~K}$ near $84 \mathrm{~km}$ before increasing with altitude into the thermosphere. There is a calculated maximum near 94 $\mathrm{km}$ associated with strong nighttime HOx heating and a secondary minimum from $\mathrm{CO}_{2}$ cooling but the general temperature trend is increasing with altitude which is different from that of the equinox simulation. Altough the HOx heating maximum produces a stronger temperature bulge than is observed by the lidar, the calculated profile is qualitatively similar to the observations.

The overall profile change can be understood by examining the zonal mean temperature contours calculated for winter solstice conditions as shown in Fig. 3(d). The main difference between the winter and summer solstice profiles, compared to the near radiative equilibrium profile of equinox, is caused by the compressional heating and expansion cooling of the mean motions respectively. It is well known that momentum deposition of breaking gravity waves in the mesosphere reverses the zonal winds, drives a strong mean meridional circulation, and produces a very cold summer and warm winter mesopause as shown in Fig. 3(d). In the winter hemisphere this additional dynamic heating acts to change the near radiative equilibrium equinox profile to the profile shown in Fig. 3(b). The cold summer mesopause is seen in the high southern (summer hemisphere) latitudes in Fig. 3(d) with a general temperature increase to higher latitudes in winter. The departures from the equinox profile are driven by dynamics in both cases and the magnitude of the departures are dependent upon the magnitude of the gravity wave forcing.

\section{Profiles of the annual and semi-annual temperature variations.}

The amplitudes and phases of the annual and semiannual temperature variations measured at Colorado and Southern France are shown in Figs.4(a)-(d) along with those deduced from CIRA 1986 for $40^{\circ} \mathrm{N}$ and $45^{\circ} \mathrm{N}$. There is general agreement in the annual amplitude for altitudes above $50 \mathrm{~km}$ and in the annual phase up to $99 \mathrm{~km}$. Both measured peak annual amplitudes occur at $86 \mathrm{~km}$, with Colorado value $4: 5 \mathrm{~K}$ cooler, in agreement with the CIRA 1986 profiles which show peaks at $85 \mathrm{~km}$ with value at $40^{\circ} \mathrm{N} 6 \mathrm{~K}$ cooler than that at $45^{\circ} \mathrm{N}$. The latitude difference in radiative and gravity wave heating is mainly responsible for this South-North temperature difference. Both CIRA 1986 and measured profiles show nodes near 65 and $\sim 100$ $\mathbf{k m}$ in the annual amplitude. As the profiles of annual phase indicate, the annual temperature variation between these nodes is out-of phase with the mean flux of solar forcing. Thus our lidar measurements confirm, for the entire altitude range, this key aspect of the mesosphere, as previous modeling and observations have shown. To reflect wavedriven circulation in this region, we may more correctly regard the atmosphere near the peak annual variation, at 86 $\mathrm{km}$, as the mesopause of the atmosphere.

Unlike the CIRA 1986 profiles, there exist strong semi-annual oscillations (SAO) at $64 \mathrm{~km}, 80 \mathrm{~km}$ and 102 $\mathrm{km}$ in the measured profiles, Fig. 4(c). Similar SAO at -65 and $\sim 80 \mathrm{~km}$ were reported from the SME observations [Clancy et al., 1994]. The SAO at $80 \mathrm{~km}$, peaked slightly
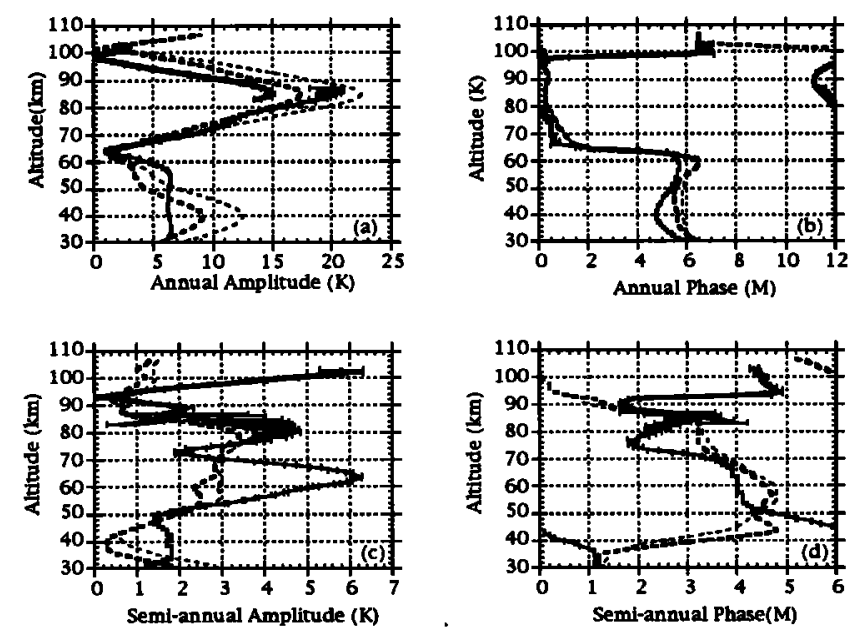

Fig. 4. Profiles of annual amplitude (a), annual phase (b), semi-annual amplitude (c) and semi-annual phase (d) from harmonic analysis $(30-110 \mathrm{~km})$. The broad and thin solid curves are from $\mathrm{Na}$ temperature lidar and Rayleigh lidar, respectively. The broad and thin broken curves are taken from CIRA 1986 for $40^{\circ} \mathrm{N}$ and $45^{\circ} \mathrm{N}$, respectively. 
before equinox, may be related to the semi-annual variations in ozone concentration [Garcia and Solomon, 1985]. As in CIRA 1986, the observed semi-annual amplitude reaches a sharp upper minimum at $\sim 93 \mathrm{~km}, 5 \mathrm{~km}$ below the upper node of the observed annual amplitude. Above this altitude, both annual and semi-annual amplitudes increase with altitude, suggesting radiative dominance in the thermosphere. Unlike CIRA 1986, a clear midlatitude SAO that resembles the SME observed strong equatorial SAO at $90 \mathrm{~km}$ [Clancy et al., 1994] is observed at $\sim 102 \mathrm{~km}$.

Like the annual mean, the annual and semi-annual amplitudes and phases measured at Colorado and Southern France match each other very well between 83 and $87 \mathrm{~km}$; the measured profiles can indeed be combined into one, giving a zonal averaged profiles extending from 30 to 105 km.

\section{Conclusion}

The nightly averaged temperatures between 81 and 90 km observed regularly over a period of three consecutive years at midlatitude sites across the Atlantic by two different lidar techniques are shown to track one another. Their details are investigated by harmonic analyses of the measured temperature profiles between 83 and $103 \mathrm{~km}$ over Colorado and between 30 and $87 \mathrm{~km}$ over Southern France. While the annual mean temperatures between 30 and $80 \mathrm{~km}$ are in agreement with the reference atmosphere of CIRA 1986 , the measured double minima in the mesopause region is not compatible with any reference atmosphere known. The new 3D TIME-GCM model simulation which included known mechanisms of chemical heating as well as gravity and tidal wave perturbations however gives temperature profiles in this region that compares qualitatively well with the measured ones. This agreement suggests the importance of the exothermic HOx chemistry and provides a basis for detailed understanding of the heating and cooling mechanisms and for fine-tuning the TIME-GCM.

The measured profiles of annual and semi-annual temperature variations have been compared with those deduced from CIRA 1986. The profiles of annual amplitude and phase clearly depict a region in the midlatitude middle atmosphere between 65 and $99 \mathrm{~km}$ with circulations controlled by dynamics. A $4.5 \mathrm{~K}$ difference between the annual amplitude maxima at $86 \mathrm{~km}$ between sites across the Atlantic is due to the South-North gradient between $41^{\circ} \mathrm{N}$ and $44^{\circ} \mathrm{N}$. Within experimental errors, the measured profiles of temperature variations match each other in the upper mesosphere where both data sets overlap. These profiles suggest that the data sets may be combined to form zonal mean profiles extending from 30 to $105 \mathrm{~km}$. The general consistency and continuity of measured temperature profiles by different lidar techniques at mid-latitude sites across the Atlantic suggest not only the value of regular observations of using collocated Rayleigh and narrowband resonance lidars but the fact that two or three such state-ofthe-art lidar stations, strategically located at each of the equatorial, midlatitude, and polar regions will be sufficient for the continued monitoring and climatological studies of the middle atmosphere.

Acknowledgments. The work at Colorado State was supported in part by NSF Grants ATM 93-01436 and
ATM 94-15853. The work at NCAR is sponsored by NSF and partially by the NASA Space Physics Theory Program (S-97239-E). One of us (She) gratefully acknowledges helpful discussions on SAO with Todd Clancy.

\section{References}

Clancy, R. T., D. W. Rusch and M. T. Callan, Temperature minima in the averaged thermal structure of the middle mesosphere $(70-80 \mathrm{~km})$ from analysis of 40-92 km SME global temperature profiles, J. Geophys. Res., 99, 19001-19020, 1994.

Fleming, E. L., S. Chandra, J. J. Barnett, and M. Corney, Zonal mean temperature, pressure, zonal wind and geopotential height as functions of latitude, Adv. Space Res. 10, 11-59, 1990.

Garcia, R. R. and S. Solomon, a numerical model of zonally averaged dynamical and chemical structure of the middle atmosphere, J. Geophys. Res., 88, 1379$1400,1983$.

Gavrilov, N.M. and R.G.Roble, The effect of gravity waves on the global mean temperature and compositional structure of the upper atmosphere, J. Geophys. Res., in press, 1995.

Hauchecorne, A., M. L. Chanin and P. Keckhut, Climatology and trends of the middle atmospheric temperatire $(33-87 \mathrm{~km})$ as seen by Rayleigh lidar over the south of France, J. Geophys. Res., 96, 15297 15309, 1991.

Hedin, A. E., A revised thermospheric model based on mass spectrometer and incoherent scatter data: MSIS-83, J. Geophys. Res., 88, 10170-10185, 1983.

Meriwether, J. W. and M. G. Mlynczak, Is chemical heating a major cause for the mesosphere temperature inversion layer?, J. Geophys. Res. (in press), 1995.

Mlynczak, M. G. and S. Solomon, A detailed evaluation of heating efficiency in the middle atmosphere, $J$. Geophys. Res., 98, 10517-10541, 1993.

Roble, R. G., and E. C. Ridley, A thermosphereionosphere-electrodynamics general circulation model (TIME-GCM): Equinox solar cycle minimum simulation $(30-500 \mathrm{~km})$, Geophys. Res. Lett., 21, 417-420, 1994.

She, C. Y., J. R. Yu and H. Chen, Observed thermal structure of a midlatitude mesopause, Geophys. Res. Lett., 20, 567-570, 1993.

Yu, J. R. and C. Y. She, Climatology of a midlatitude mesopause region observed by a lidar at Ft. Collins, CO, J. Geophys. Res., in press, 1995.

C. Y. She, and David A. Krueger, Physics Department, Colorado State University, Fort Collins, CO 80523, USA

J. R. Yu, Department of Electrical Engineering, University of Illinois, Urbana, IL 61820, USA

Raymond Roble, High Altitude Observatory, NCAR, Boulder, CO 80307, USA

Philippe Keckhut, Alain Hauchecorne and Marie-Lise Chanin, Service d'Aeronomie du CNRS, Verrieres le Buisson Cedex, 91371, France

(Received Nov. 15, 1994; accepted Dec. 15, 1994) 